\title{
Electrogeneration of Gold Nanoparticles on Porous-Carbon Paper- Based Electrodes and Application to Inorganic Arsenic Analysis in White Wines by Chronoamperometric Stripping
}

\author{
Estefanía Nunez-Bajo, M. Carmen Blanco-López, Agustín Costa-García, \\ and M. Teresa Fernández-Abedul*il \\ Departamento de Química Física y Analítica, Universidad de Oviedo, Asturias, Spain 33006 \\ Supporting Information
}

ABSTRACT: This paper describes the development of simple, sustainable, and low-cost strategies for signal enhancement on paper-based carbon platforms through gold nanoparticles electrogenerated from small volumes of tetrachloroauric (III) acid solutions. Carbon ink is deposited on a hydrophilic working area of the paper delimited with hydrophobic wax. This maskless procedure is fast and cuts down ink waste. The connection of this working electrode to the potentiostat is ensured with the use of screen-printed electrodes (SPEs). Close contact of the whole area of both carbon electrodes improves the precision of the nanostructuration. Resulting gold-modified paper-based carbon working electrodes (AuNPs-PCWEs) were characterized by cyclic voltammetry (CV), electrochemical impedance spectroscopy (EIS), scanning electron microscopy (SEM), and electron dispersion X-ray spectrometry (SEM/EDX). This methodology was applied for the first time to the inorganic arsenic determination in commercial white wines by chronoamperometric stripping of the electrodeposited $\mathrm{As}(0)$. In an optimized system, $\mathrm{As}(\mathrm{III})$ was reduced and deposited as $\mathrm{As}(0)$ on the nanostructured surface by applying a potential of $-0.3 \mathrm{~V}$ during $180 \mathrm{~s}$. Then, anodic stripping chronoamperometry was performed at $+0.4 \mathrm{~V}$. The analytical signal was the current recorded at $30 \mathrm{~s}$. On the other hand, As(V) was chemically reduced to As(III) with $0.2 \mathrm{M} \mathrm{KI}$, and total determination of arsenic could be carried out. As $(\mathrm{V})$ was determined as the difference between total As and As(III). Then, this fast, simple and low-cost method can be employed for speciation purposes. Limits of detection for As(III) and total arsenic (in the presence of $\mathrm{KI}$ ) are $2.2 \mu \mathrm{g} \mathrm{L}^{-1}$ and $2.4 \mu \mathrm{g} \mathrm{L}^{-1}$, respectively, and indicate that this method is suitable for regulated quality control.

$\mathrm{N}$ ew strategies for rapid analysis without sophisticated instrumentation are currently required in clinical, food, and environmental fields. ${ }^{1}$ Moreover, this trend is expected to continue rising while we are immersed in the information era. In this scenario, both Analytical Chemistry and Data Management are disciplines of paramount importance. The former would be responsible for obtaining data, which will be subsequently converted into useful information to solve today's societal problems. ${ }^{2}$ In this context, small and low-cost analytical devices that can be used by inexperienced personnel to produce accurate and precise data are highly demanded. Electrochemical detection fits perfectly with these requirements; miniaturization is a current trend affecting not only the sensing elements (with the use of, e.g., disposable complete electrochemical cells ${ }^{3,4}$ or mass-produced common elements as electrodes ${ }^{5,6}$ ) but also the instrumentation. ${ }^{3,7,8}$ Calibration- and maintenance-free electrochemical sensors are a real possibility at present. ${ }^{9}$ However, basic analytical properties have to be also fulfilled. Sensitive detection is very often a challenge, and nanostructuration of electrodes has been a common approach. ${ }^{10}$ Carbon nanotubes $^{10,11}$ and gold nanoparticles (AuNPs) ${ }^{12,13}$ have been widely employed for this purpose at different types of working electrodes. ${ }^{12-16}$ However, their use at paper-based electrodes is much scarcer, with the first integration of electrochemical detection in microfluidic paper analytical devices ( $\mu$ PADs) dating back to less than a decade. ${ }^{17}$

Several methods for electrode fabrication and incorporation into microfluidic paper analytical devices ( $\mu$ PADs) have been developed. ${ }^{18-20}$ Although wire electrodes can be used, ${ }^{21-23}$ the most common methods involve using a screen ${ }^{17}$ or stencil ${ }^{18}$ to pattern conductive carbon or metallic inks onto paper to create complete three-electrode cells following a thick-film procedure. Carbon has been the most common electrode material even electrofluidic carbon platforms have been recently reported. ${ }^{24}$ Metallic electrodes provide their own unique advantages and thin-film methods based on sputtering have been used. ${ }^{23}$ On the other hand, maskless procedures for fabricating paper-based

Received: January 13, 2017

Accepted: May 22, 2017

Published: May 22, 2017 


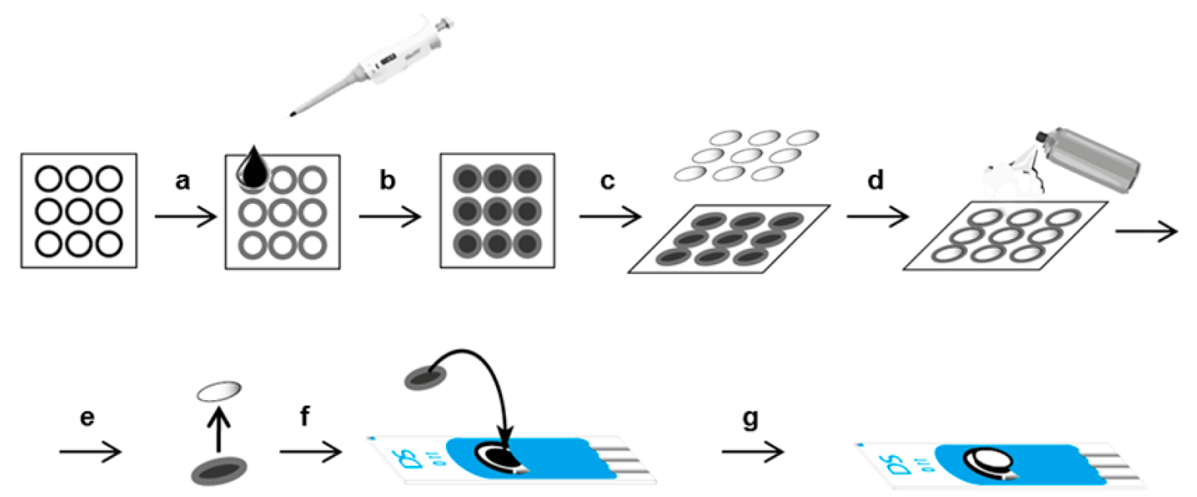

Figure 1. Schematic representation of the fabrication and coupling of paper-based carbon working electrodes (PCWEs): (a) Wax-melting at $110{ }^{\circ} \mathrm{C}$ during 2 min after wax-printing, (b) carbon ink deposition, (c) protection of the conductive layer with plastic covers, (d) addition of spray adhesive, (e) removal of the plastic cover after cutting the PCWE, (f) placement of the PCWE over the SPCE, and (g) final platform composed by the PCWE with external reference and counter electrodes from the SPCE.

electrodes have been followed using computer-controlled plotters $^{25}$ or inkjet printers. ${ }^{26}$ Nevertheless, simpler protocols could be employed for both, carbon or metals, if the reference and auxiliary electrodes are external. ${ }^{23,27}$ In this case, a maskless gold-sputtering process $^{23}$ or simple carbon-ink drop casting ${ }^{27}$ on the paper substrate were carried out.

Nanostructuration of paper-based electrodes with gold is usually made through the deposition of previously prepared gold nanoparticles by chemical reduction of tetracloroauric (III) acid. ${ }^{2,29}$ They could be then used either as a seed for the further growth of interconnected particles ${ }^{28}$ or added to the paper substrate together with the carbon component. ${ }^{29}$ Electrochemical deposition represents a rapid methodology to generate gold nanostructures. ${ }^{28}$ Moreover, the same equipment can be used for nanostructure electrogeneration and analyte detection with a good control of the process through the current driven (or potential applied). AuNPs have been electrodeposited from a potassium cyanoaurate (III) solution on lignocellulose/graphite composite sheets included in an electrochemical cell. ${ }^{30}$ In this paper we propose for the first time the electrodeposition of AuNPs on paper electrodes based on carbon ink, using very small volumes of the plating solution. We have used screen-printed electrodes (SPEs) as support and connection for the paper-based electrode, that acts as the working electrode of the electrochemical cell. This design allows: (i) adequate connection between the two carbon surfaces (that of the SPE and that of the paper substrate), with close contact to generate gold nanostructures on the carbonaceous inner surface of the paper, and (ii) reusability of the SPE (if it is wanted) since the outer carbon area of the paper covers all the surface of the SPE working electrode and its thickness impedes the wetting.

Metal ion determination in food and environmental samples is a critical issue. The use of AuNPs-modified electrodes has improved the selectivity and sensitivity of the determination of $\mathrm{Cr}(\mathrm{VI}), \mathrm{Zn}$ (II), or $\mathrm{Cu}(\mathrm{II}) .^{31,32}$ On the other hand, our group has also reported heavy metal detection using carbon electrodes in low-cost substrates (transparency films) suitable for field analysis. ${ }^{33}$ In contrast, paper substrates allow passive transport by capillarity. As a proof-of-concept, in this paper, we demonstrate the possibilities of this platform for electroanalytical determination of inorganic arsenic in wines. Arsenic may cause toxic effects on humans and other animals, with the predominant exposure being at diet habits, and it is usually present in wine as a consequence of herbicides and insecticides used for grape production. Its concentration depends on the soil type, kind of process employed for wine production, and wine storage conditions. ${ }^{34}$ The maximum total arsenic concentration permissible in wines (European norm) ${ }^{35}$ is 200 $\mu \mathrm{g} \mathrm{L}^{-1}$. Its toxicity depends strongly on its chemical form and quantity. ${ }^{36}$ Thus, arsenic speciation is essential for assessing arsenic toxicity in foodstuffs. Sensitive methods for the arsenic determination (with LODs comprised between $2.5 \mathrm{ng} \mathrm{L}^{-1}$ and $0.9 \mu \mathrm{g} \mathrm{L}^{-1}$ ) with AuNPs-modified carbon electrodes have been reported. ${ }^{37-56}$ However, all of them use substrates different from paper (e.g., glassy carbon, ${ }^{41-43}$ carbon paste ${ }^{44}$ or screenprinted carbon electrodes $\left.{ }^{45,46}\right)$. In this work, we have developed a low-cost sensor for the field determination of inorganic arsenic in wines by using nanostructured carbon-ink paper electrodes. Arsenic was electrochemically deposited and subsequently determined by anodic stripping. This method (i) is sensitive enough to allow normative control, (ii) requires very simple instrumentation, (iii) is based on the use of AuNPs, which allow reproducible reoxidation during the stripping step, $^{47}$ (iv) requires a very small volume of gold solutions for the nanostructuration, which increases the sustainability, (v) avoids possible errors due to the color and turbidity of the samples, (vi) allows to carry out speciation analysis, ${ }^{37,48}$ and (vi) does not require sample preparation, because it is not subjected to matrix interferences observed by spectroscopic methods. ${ }^{49,50}$ Although platinum ${ }^{51}$ and gold $^{46}$ nanoparticles have been used as modifiers at conventional SPEs for the As(III) determination in drinking water, this is the first time they are tested using paper as the electrode substrate.

The priorities of sustainable development have been considered in this method, which meets the green analytical chemistry principles ${ }^{52}$ as follows: simplified sample treatment, minimal sample size, in situ measurements, reduced use of reagents, miniaturized instrumentation, low waste volumes, and low energy requirements. Accordingly, even the possibility of reusing the SPCEs (included in our work) goes along with these environmental concerns. In addition, the electrochemical generation of AuNPs from a tetrachloroaurate(III) solution developed in this work does not involve the use of toxic or high-risk reagents.

\section{EXPERIMENTAL SECTION}

Materials, Equipment, and Chemicals. Whatman chromatographic paper grade 1 was obtained from GE Healthcare Life Sciences (U.K.). Transparency sheets were 
acquired from local stationeries. Potassium ferrocyanide trihydrate $\left(\mathrm{K}_{4}\left[\mathrm{Fe}(\mathrm{CN})_{6}\right] \cdot 3 \mathrm{H}_{2} \mathrm{O}\right), 1000 \mathrm{mg} \mathrm{L}^{-1} \mathrm{As}(\mathrm{V})$, and $1000 \mathrm{mg} \mathrm{L}^{-1} \mathrm{As}$ (III) standard solutions for inductively coupled plasma mass spectrometry (ICP-MS) were purchased from Sigma-Aldrich. Titrisol Gold-Standard $10.15 \mathrm{mM} \mathrm{AuCl}_{4}{ }^{-}$in 2 $\mathrm{M} \mathrm{HCl}$ solution, $1000 \mathrm{Ge} \mathrm{mg} \mathrm{L}^{-1}$ standard solution for ICPMS, sodium hydroxide, potassium iodide, potassium chloride, hydrochloric acid (37\%), nitric acid (65\%), orthophosphoric acid (90\%), and ethanol (100\%) were supplied by Merck. All the solutions were prepared in Milli-Q water (Merck Millipore).

Hydrophobic areas were printed with a wax printer model ColorQube 8570 DS (Xerox). Cyclic voltammetry, chronoamperometry, chronopotentiometry, and electrochemical impedance spectroscopy (EIS) measurements were made using an Autolab PGSTAT potentiostat model (PGSTAT12) from Metrohm. A Mettler Toledo (AB54) balance, a Crison Micro-pH 2001 pH-meter and a magnetic stirrer Asincro (J. P. Selecta) were used. GPES and FRAT computer programs were used for electrochemical measurements. Mass spectrometry measurements were carried out with an ICP-MS model iCAP RQ (Thermo Fisher Scientific). Screen-printed carbon electrodes (SPCEs), model DS-110, were obtained from DropSens. White wine samples (with $11 \% \mathrm{v} / \mathrm{v}$ in ethanol) were purchased from a local grocery (Asturias, Spain).

Preparation of Paper-Based Carbon Electrodes. Grade 1 Whatman chromatographic paper was wax-printed with a pattern designed with the software Adobe Illustrator CC. The pattern consisted of $6 \mathrm{~mm}$ diameter circles with $0.7 \mathrm{~mm}$ of drawing stroke in order to obtain circles with $4 \mathrm{~mm}$ of diameter after wax melting on a hot plate at $110{ }^{\circ} \mathrm{C}$ during $2 \mathrm{~min}$ to create hydrophobic barriers (Figure 1a). Once the wax was melted, a volume of $2 \mu \mathrm{L}$ of a $24 \%$ carbon ink suspension in dimethylformamide was dropped over each circle leaving the solvent to evaporate for $1 \mathrm{~h}$ at $70{ }^{\circ} \mathrm{C}$ (Figure $1 \mathrm{~b}$ ). Conductive layers were protected (Figure 1c) with plastic covers $(4 \mathrm{~mm}$ circles of transparency sheet) and a spray adhesive was applied (Figure 1d). The glue was deposited on the hydrophobic area made of wax. Covers were removed, and the sheets were cut into $4.5 \mathrm{~mm}$ round discs using a paper punch (Figure 1e). As a result, adhesive working conductive discs with $4 \mathrm{~mm}$ hydrophilic area and $0.5 \mathrm{~mm}$ hydrophobic adhesive perimeter were obtained.

Finally, SPCEs were washed with Milli-Q water and dried. In this case, the working electrode of the SPCE acted as a connection for electrodeposition since the paper-based working electrode (PWE) was placed just on top. The adhesive side was located over the surrounding ceramic in such a way that the conductive layer is in direct contact with the SPE carbon spot (Figure 1f). The silver pseudoreference and carbon counter electrodes of the SPCE card acted as external electrodes (Figure 1g).

Gold Nanostructuration. The paper carbon working electrode (PCWE) was coupled to the SPCE and connected to the potentiostat. Then, a volume of $50 \mu \mathrm{L}$ of $\mathrm{HAuCl}_{4}$ solutions in $2 \mathrm{M} \mathrm{HCl}$ was deposited over the whole cell (paperbased working electrode, silver pseudoreference, and carbon counter electrode).

Generation of gold nanoparticles (AuNPs) was carried out comparing two electrochemical methods, chronopotentiometry and multicyclic voltammetry. In the first case, a current $(-100$ $\mu \mathrm{A})$ flows during a fixed time $(360 \mathrm{~s})$ and, in multicyclic voltammetry, the potential is scanned 45 times between +0.1 and $+0.5 \mathrm{~V}$ vs silver pseudoreference electrode at a scan rate of $100 \mathrm{mV} \mathrm{s}^{-1}$ ). After this step, $+0.12 \mathrm{~V}$ were applied to the working electrode during $240 \mathrm{~s}$ in order to remove the hydrogen in both cases.

Finally, the gold-modified paper-based carbon working electrode (AuNPs-PCWE) was peeled-off from the SPCE employed for the electrodeposition and placed on another clean SPCE for electrochemical detection, assuring AuNPs have been generated onto paper-based electrodes instead of on the surface of the screen-printed working electrode. Comparison between both AuNPs generation methods was carried out recording cyclic voltammograms in $100-\mu \mathrm{M}$ potassium ferrocyanide solution in $0.1 \mathrm{M}$ phosphate buffer (PB), $\mathrm{pH}$ 7.0, and $0.1 \mathrm{M}$ in $\mathrm{KCl}$.

Sample Treatment and Electrochemical Analysis. A simple procedure reported in the bibliography for wine sample treatment was followed, with just some modifications at the final volume. ${ }^{53}$ Briefly, for As(III) determination, a volume of $500 \mu \mathrm{L}$ of unfiltered samples was mixed with $7.5 \mu \mathrm{L}$ of $1 \mathrm{mg}$ $\mathrm{L}^{-1}$ As(III) standard solution (to ensure an As(III) content higher than $10 \mu \mathrm{g} \mathrm{L}^{-1}$ ) and diluted with $9 \mathrm{M} \mathrm{HCl}$ solution until a final volume of $750 \mu \mathrm{L}$. Calibration curves were obtained by dilution of a $1 \mathrm{mg} \mathrm{L}^{-1} \mathrm{As}$ (III) standard solution with $3 \mathrm{M} \mathrm{HCl}$.

For total arsenic determination, a previous reduction step of As $(\mathrm{V})$ to As(III) was carried out. The unfiltered sample was diluted in a proportion $2: 3(\mathrm{v}: \mathrm{v})$ in such a way that the final solution contained $0.2 \mathrm{M} \mathrm{KI}, 5 \mu \mathrm{g} \mathrm{L}^{-1}$ of As(III) and $5 \mu \mathrm{g} \mathrm{L}^{-1}$ of $\mathrm{As}(\mathrm{V})$ in a final $3 \mathrm{M}$ concentration of $\mathrm{HCl}$. Calibration curves were obtained by dilution of a mixture of $50 \mu \mathrm{g}$

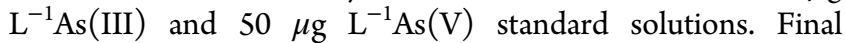
solutions contained $0.2 \mathrm{M} \mathrm{KI}$, and the final concentration of $\mathrm{HCl}$ was $3 \mathrm{M}$. $\mathrm{KI}$ was added at the end to avoid oxidation to iodine. Tubes were heated at $80{ }^{\circ} \mathrm{C}$ until the colorless solution turned to light yellow, which indicated $\mathrm{I}_{2}$ formation ( $\sim 5 \mathrm{~min}$ ). Then, solutions were cooled to room temperature in the dark, placed into the electrochemical cell and analyzed.

Electrochemical determination of As(III) and total arsenic was carried out by chronoamperometry in two successive steps: (i) a deposition process where As(III) is electrochemically reduced to $\mathrm{As}(0)$ applying $-0.3 \mathrm{~V}$ vs silver pseudoreference electrode during $180 \mathrm{~s}$, and (ii) a stripping process where As $(0)$ is reoxidized to As(III) applying $+0.4 \mathrm{~V}$ vs silver pseudoreference electrode during $30 \mathrm{~s}$.

Sample Treatment for ICP-MS Analysis. A volume of 1 $\mathrm{mL}$ of sample was mixed with $50 \mu \mathrm{L}$ of $1 \mathrm{mg} \mathrm{L}^{-1} \mathrm{Ge}$ internal standard and diluted with $0.1 \% \mathrm{HNO}_{3}$ up to a final volume of $10 \mathrm{~mL}$. Calibration solutions in a $0.5-25 \mu \mathrm{g} \mathrm{L}{ }^{-1}$ As(III) range of concentrations were prepared by adding $50 \mu \mathrm{L}$ of Ge internal standard solution and $110 \mu \mathrm{L}$ of $100 \%$ ethanol to the appropriate volume of a $1 \mathrm{mg} \mathrm{L}^{-1}$ As solution and making up to $10 \mathrm{~mL}$ with $0.1 \% \mathrm{HNO}_{3}$. ICP-MS main conditions were forward power of $1550 \mathrm{~W} ; 14.0 \mathrm{~L} \mathrm{~min}^{-1}, 0.8 \mathrm{~L} \mathrm{~min}^{-1}$, and 1.05 $\mathrm{L} \mathrm{min}^{-1}$ flows of cool gas, auxiliary gas, and nebulizer, respectively.

Electron Microscopy Study. The topography of the PCWEs and Au-PCWEs was examined by scanning electron microscopy (SEM). For these studies, samples were placed perpendicularly to the electron beam with a working distance of $10 \mathrm{~mm}$ and $20 \mathrm{kV}$ of extraction tension in a JEOL (model 6610LV) microscope with an electron dispersion X-ray (EDX) attachment. 
A

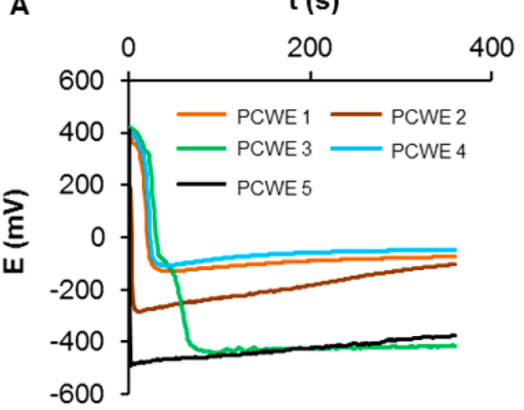

C

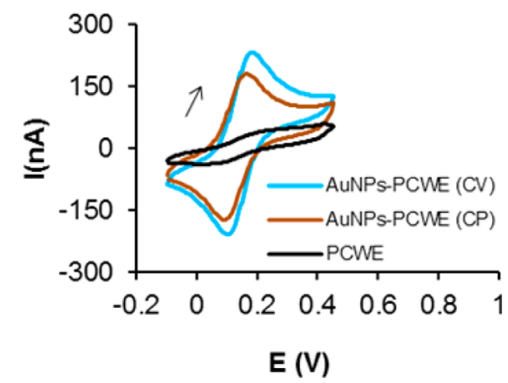

B

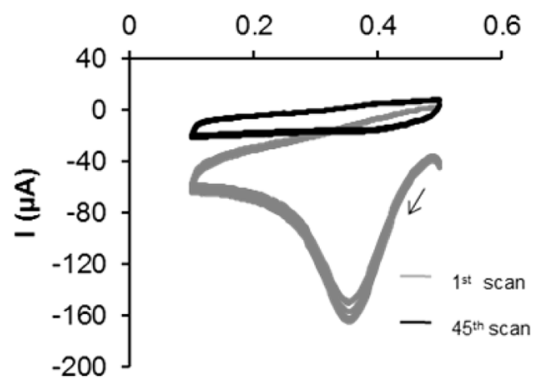

D

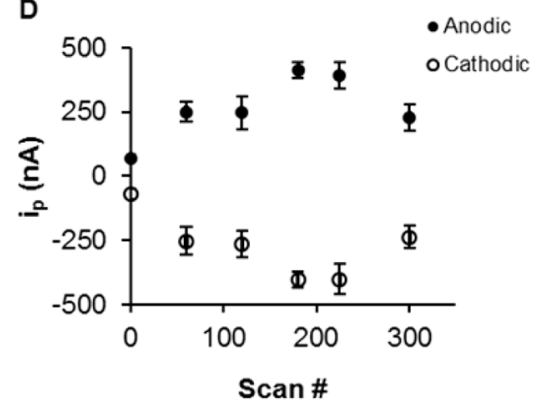

Figure 2. (A) Chronopotentiograms obtained in five different PCWEs for AuNPs electrogeneration from a $10.15 \mathrm{mM} \mathrm{AuCl}_{4}^{-}$solution in $2 \mathrm{M} \mathrm{HCl}^{\text {. }}$ Deposition current of $-100 \mu \mathrm{A}$ during $360 \mathrm{~s}$. (B) First and last cyclic voltammograms recorded in a $10.15 \mathrm{mM} \mathrm{AuCl}_{4}^{-}$solution in $2 \mathrm{M} \mathrm{HCl}^{\circ}$ on five different PCWEs sweeping the potential from +0.5 to $+0.1 \mathrm{~V}$ vs Ag pseudoreference electrode at a scan rate of $100 \mathrm{mV} \mathrm{s}^{-1}$. (C) Cyclic voltammograms obtained sweeping the potential from -0.15 to $+0.45 \mathrm{~V}$ at $100 \mathrm{mV} \mathrm{s}^{-1}$ in a $100 \mu \mathrm{M} \mathrm{K}_{4}\left[\mathrm{Fe}(\mathrm{CN})_{6}\right]$ solution in $0.1 \mathrm{M} \mathrm{PB}(\mathrm{pH} 7.0)$ and $0.1 \mathrm{M}$ in $\mathrm{KCl}$ using a PCWE and a AuNPs-PCWE where AuNPs were generated by galvanostatic (chronopotentiometric record) or potentiostatic (cyclic voltammograms) methods. (D) Anodic and cathodic peak currents obtained by cyclic voltammetry (sweeping the potential from -0.15 to $+0.45 \mathrm{~V}$ at $100 \mathrm{mV} \mathrm{s}^{-1}$ ) in a $100 \mu \mathrm{M} \mathrm{K}_{4}\left[\mathrm{Fe}(\mathrm{CN})_{6}\right]$ solution in $0.1 \mathrm{M} \mathrm{PB} \mathrm{(pH} \mathrm{7.0)} \mathrm{with} \mathrm{0.1} \mathrm{M} \mathrm{KCl} \mathrm{using} \mathrm{AuNPs-PCWEs.} \mathrm{AuNPs}$ were generated by cyclic voltammetry with a different number of scans (electrodeposition time).

\section{RESULTS AND DISCUSSION}

Gold Electrodeposition. A carbon-ink paper electrode was employed as the substrate for gold nanoparticles (AuNPs), generated by electrochemical reduction of tetrachloroauric (III) acid. Chemical generation, although possible, would not guarantee electrical connection among them and the $\mathrm{WE}$, whereas electrogeneration implies direct reduction of $\mathrm{Au}(\mathrm{III})$ on the carbon electrode surface and therefore, a close connection is ensured. The electrochemical processes of $\mathrm{Au}(\mathrm{III})$ on PCWEs are indicated in Figure S1. We took as reference the methods developed by our research group ${ }^{12}$ for direct electrodeposition on SPCEs. AuNPs were in situ generated by applying a constant current of $-100 \mu \mathrm{A}$ during $6 \mathrm{~min}$, in a $10.15 \mathrm{mM}$ acidic solution of $\mathrm{AuCl}_{4}^{-}$(galvanostatic electrogeneration). Reduction of $\mathrm{Au}(\mathrm{III})$ to $\mathrm{Au}(0)$ was produced, and a chronopotentiogram ( $E$ vs $t$ curve) is recorded. On the other hand, potentiostatic routes, in which the required potential is constantly applied to the electrode, or scanned in the right window, are also possible. In these cases, a chronoamperogram ( $I$ vs $t$ curve) or voltammogram ( $I$ vs $E$ curve) can be recorded. In this work, we have applied cyclic voltammetry (CV) using $50 \mu \mathrm{L}$ of $10.15 \mathrm{mM} \mathrm{AuCl}_{4}^{-}$acidic solution and sweeping the potential 45 times (equivalent to 6 $\min$ ) in the negative sense, from $+0.5 \mathrm{~V}$ to $+0.1 \mathrm{~V}$, at $100 \mathrm{mV}$ $\mathrm{s}^{-1}$. This potential range was chosen in order to avoid the production and adsorption of hydrogen (see Figure S2). Reproducibility was studied by repeating each electrodeposition in five devices (Figure 2A). As it could be noted, very different stabilization potentials were obtained in the galvanostatic route, with a difference of 1 order of magnitud (from 40 to $400 \mathrm{mV}$ ). The stabilization potential is related to the total consumption of $\mathrm{Au}(\mathrm{III})$, since it is completely reduced to $\mathrm{Au}(0)$. The difference between stabilization potentials indicates, at first instance, that the galvanostatic method is not adequate for AuNPs electrodeposition on PCWEs. The time required for this stabilization was also very different. On the other hand, more reproducible signals were obtained for the potentiostatic (cyclic voltammetry) method, since voltammograms recorded in five PCWEs are almost overlapped (Figure 2B). The reduction process of As(III) to As $(0)$ took place at a peak potential of $+375 \pm 8 \mathrm{mV}$. Figure S3 shows the 45 scans recorded for the gold electrodeposition on a single device. The lack of precision also relies on the simultaneous reduction of $\mathrm{H}^{+}$from the medium to $\mathrm{H}_{2}$. Therefore, after the AuNPs generation by both methods, a potential of $+0.12 \mathrm{~V}$ was applied during 4 min to desorb the hydrogen.

The $\mathrm{H}_{2}$ generation not only affects the deposition, but its oxidation process could interfere in the As determination because it takes place at similar potentials than that of the oxidation of As(0) to As(III) (see Figure S4). In addition, the hydrogen generated during the electrolysis plays the role of reducing agent for $\mathrm{As}(\mathrm{V})$ on $\mathrm{Au}$ and/or Pt electrodes which could interfere in the subsequent $\mathrm{As}(\mathrm{III})$ determination. ${ }^{54,55}$ After the electrodeposition, nanostructured surfaces (both types, chronopotentiometrically or $\mathrm{CV}$ generated) were characterized by recording cyclic voltammograms. Anodic and cathodic peak currents, obtained in a $100 \mu \mathrm{M} \mathrm{K}_{4}\left[\mathrm{Fe}(\mathrm{CN})_{6}\right]$ solution in $0.1 \mathrm{M} \mathrm{PB} \mathrm{pH} 7.0(0.1 \mathrm{M} \mathrm{KCl})$ were compared. The electrochemical process of the ferro/ferri system is shown in 
the CVs of the Figure 2C. Both, chronopotentiometric (CP) and cyclic voltammetric (CV), methods showed considerable signal and reversibility enhancement of the process compared to the unmodified PCWE. The ratio between anodic and cathodic peaks changed from $0.81 \pm 0.04$ (unmodified PCWEs) to $0.99 \pm 0.12$ (CP method) and $1.02 \pm 0.05$ (CV method). The difference between anodic and cathodic potentials changed from the value of a quasireversible process, $110 \pm 6 \mathrm{mV}$ to that of an almost reversible process, $61 \pm 6 \mathrm{mV}$ (CP) and $64 \pm 5 \mathrm{mV}(\mathrm{CV})$. However, those AuNPs-PCWEs obtained by $\mathrm{CV}$ showed more reproducible behavior and slightly higher analytical response (anodic and cathodic currents were $190 \pm 40$ and $-180 \pm 50 \mathrm{nA}$, respectively). The CP method, in turn, presented $140 \pm 90$ and $-150 \pm 70$ $\mathrm{nA}$ anodic and cathodic currents, respectively. These results suggested that the multicyclic voltammetry method is more appropriate for the construction of AuNPs-PCWEs than the chronopotentiometric method and consequently, it was employed for the rest of experiments.

Optimization of the electrodeposition time by means of the number of scans for PCWEs was carried out. Triplicates were prepared by recording CVs in a $10.15 \mathrm{mM} \mathrm{AuCl}_{4}^{-}$acidic solution under the same conditions described above and sweeping the potential 60,120, 180, 220, and 300 times. A hydrogen desorption step $(+0.12 \mathrm{~V}$ during $4 \mathrm{~min})$ was applied at the end. Anodic and cathodic peak currents obtained by CVs in a $100 \mu \mathrm{M} \mathrm{K}_{4}\left[\mathrm{Fe}(\mathrm{CN})_{6}\right]$ solution, are shown in Figure $2 \mathrm{D}$. It can be seen that 180 scans are suitable to get gold nanostructures on PCWEs that yield high and precise signals. In all the cases, there is a significant increase in the current, as compared to that of the unmodified PCWE (first point of the graph in Figure 2D). Electrogeneration of AuNPs was then carried out sweeping 180 times the potential.

On the other hand, 10.15, 5.08, and $1.00 \mathrm{mM} \mathrm{AuCl}_{4}^{-}$ solutions in $2 \mathrm{M} \mathrm{HCl}$ were used to optimize the concentration of $\mathrm{Au}(\mathrm{III})$ at the AuNPs electrogeneration by cyclic voltammetry, applying 180 scans at $100 \mathrm{mV} \mathrm{s}^{-1}$ between +0.5 and $+0.1 \mathrm{~V}$ by triplicate. The effect of the $\mathrm{Au}(\mathrm{III})$ concentration was evaluated by recording cyclic voltammograms in $\mathrm{K}_{4} \mathrm{Fe}$ $(\mathrm{CN})_{6}$ solutions with different concentration, in a range comprised between 10 and $1000 \mu \mathrm{M}$ in $0.1 \mathrm{M} \mathrm{PB} \mathrm{pH} \mathrm{7.0}$ $(0.1 \mathrm{M} \mathrm{KCl})$. Results (Table 1) show that the sensitivity

Table 1. Parameters Obtained from Calibration Plots of Anodic Currents Obtained by $\mathrm{CV}$ in $\mathrm{K}_{4}\left[\mathrm{Fe}(\mathrm{CN})_{6}\right]$ Solutions in 0.1 M PB ( $\mathrm{pH} \mathrm{7.0),} \mathrm{by} \mathrm{Using} \mathrm{AuNPs-PCWEs}{ }^{a}$

$\begin{array}{cccc}{\left[\mathrm{AuCl}_{4}^{-}\right](\mathrm{mM})} & \text { slope }\left(\mathrm{nA} \mu \mathrm{M}^{-1}\right) & \text { intercept }(\mathrm{nA}) & R^{2} \\ 10.15 & 4.56 & 37.70 & 0.9994 \\ 5.08 & 2.91 & 14.15 & 0.9999 \\ 1.02 & 1.73 & 20.40 & 0.9971\end{array}$

${ }^{a}$ AuNPs were generated by cyclic voltammetry using different concentrations of $\mathrm{Au}(\mathrm{III})$ acidic solutions.

increases with the concentration of gold complex (4.56 nA $\mu \mathrm{M}^{-1}$ for $\left.10.15 \mathrm{mM} \mathrm{AuCl}_{4}^{-}\right)$. Then, the highest concentration was chosen for the rest of the work.

Characterization of AuNPs-PCWEs. Figure $3 \mathrm{~A}-\mathrm{C}$ compares morphological features of an unmodified PCWE and a AuNPs-PCWE obtained using the optimized CV conditions. Figure $3 \mathrm{~A}$ shows a SEM image of the carbon surface obtained after depositing the ink on the chromatographic paper, and the curing process at $80{ }^{\circ} \mathrm{C}$. As it can be seen, the paper-based carbon electrode is slightly porous and rough. Figure $3 \mathrm{~B}$ corresponds to a PCWE that has been modified with gold nanoparticles connected to the carbon surface on the cellulosic fibers. AuNPs are better observed at a higher magnification micrograph (Figure 3C). EDX spectrum analysis confirmed the presence of gold and chloride ions from the $\mathrm{AuCl}_{4}^{-}$acidic solution (Figure 3D).

In addition, electron transfer resistance $\left(R_{\mathrm{et}}\right)$ values obtained from electrochemical impedance measurements (Figure $3 \mathrm{E}$ ) obtained in a $5 \mathrm{mM} \mathrm{K}_{4}\left[\mathrm{Fe}\left(\mathrm{CN}_{6}\right)\right]$ solution in $0.1 \mathrm{M} \mathrm{PB} \mathrm{pH} 7.0$ $(0.1 \mathrm{M}$ in $\mathrm{KCl})$ using unmodified SPCEs, PCWEs, and AuNPsPCWEs (in the last two cases coupled to SPCEs) were $1.6 \pm$ $0.5,3.6 \pm 0.4$, and $0.020 \pm 0.003 \mathrm{k} \Omega$, respectively. These results indicate that coupled PCWEs exhibit more resistance to the electron transfer than unmodified SPCEs and, once AuNPs are electrogenerated on PCWEs, there is a high decrease in the resistance, which confirms the presence of nanostructures on paper-based carbon electrodes.

Determination of As(III) with Nanostructured PaperBased Carbon Electrodes (AuNPs-PCWEs). Once the paper-based electrodes have been nanostructured, they were used for the As determination by anodic stripping voltammetry. Electrochemical processes recorded by cyclic voltammetry in a $200 \mathrm{mg} \mathrm{L}^{-1}$ As(III) solution in $3 \mathrm{M} \mathrm{HCl}$ are shown in Figure S4. Several works report the voltammetric determination of As(III), demonstrating that a reliable stripping signal is obtained using $\mathrm{HCl}$ and $\mathrm{HClO}_{4}$ as supporting electrolytes. Species which take part in the electron transfer reaction at the WE are $\mathrm{As}(\mathrm{OH})_{2} \mathrm{Cl}, \mathrm{As}(\mathrm{OH}) \mathrm{Cl}_{2}$, and $\mathrm{AsCl}_{3} .{ }^{56}$ In the present investigation, only $\mathrm{HCl}$ was used as supporting electrolyte for the reductive deposition of As(III) and the effect of increasing $\mathrm{HCl}$ concentration on the voltammetric response was investigated (voltammograms are shown in Figure S5 for a $200 \mathrm{mg} \mathrm{L}^{-1} \mathrm{As}$ (III) solution). When AuNPs-PCWEs and this electrolyte are used, As(III) presents a reduction process to $\operatorname{As}(0)$ at $-0.10 \mathrm{~V}$ and the corresponding reoxidation process occurs at $+0.12 \mathrm{~V}$, when the potential is swept from $-0.5 \mathrm{~V}$ to $+0.6 \mathrm{~V}$. Figure $4 \mathrm{~A}$ shows that the $\mathrm{CV}$ signal recorded using optimized AuNPs-PCWEs is higher than that recorded using the unmodified PCWEs (blue line vs black line) and SPCEs (without paper) modified with AuNPs (CP at $-100 \mu \mathrm{A}$ during $360 \mathrm{~s}$ ). Voltammograms were obtained in a $200 \mathrm{mg} \mathrm{L}^{-1} \mathrm{As}$ (III) standard solution in $3 \mathrm{M} \mathrm{HCl}$. Figure $4 \mathrm{~B}$ shows the variation of the anodic peak intensity for different $\mathrm{HCl}$ concentrations. It increases up to $3 \mathrm{M}$, where a plateau is attained. This concentration was chosen for the rest of the work.

In stripping techniques, the sensitivity of the determination depends on the amount of analyte deposited onto the working electrode surface, which is controlled by the deposition potential and deposition time. ${ }^{57}$ Initial experiments for As determination were carried out by square wave voltammetry (SWV). However, better precision and accuracy were obtained by chronoamperometry. In addition, this technique is simpler than SWV since a potential sweep is not required and signals are recorded only by fixing the potential and measuring the current with time. Then, an automatic two-step chronoamperometric program was applied. The first step consisted on the As(III) to As(0) reduction at a convenient potential, during the optimum time. The objective was to find out the instrumental conditions to get the most sensitive chronoamperometric response at $30 \mathrm{~s}$ when $\operatorname{As}(0)$ stripping was carried out (second step). The stripping potential chosen was $+0.4 \mathrm{~V}$, since it 

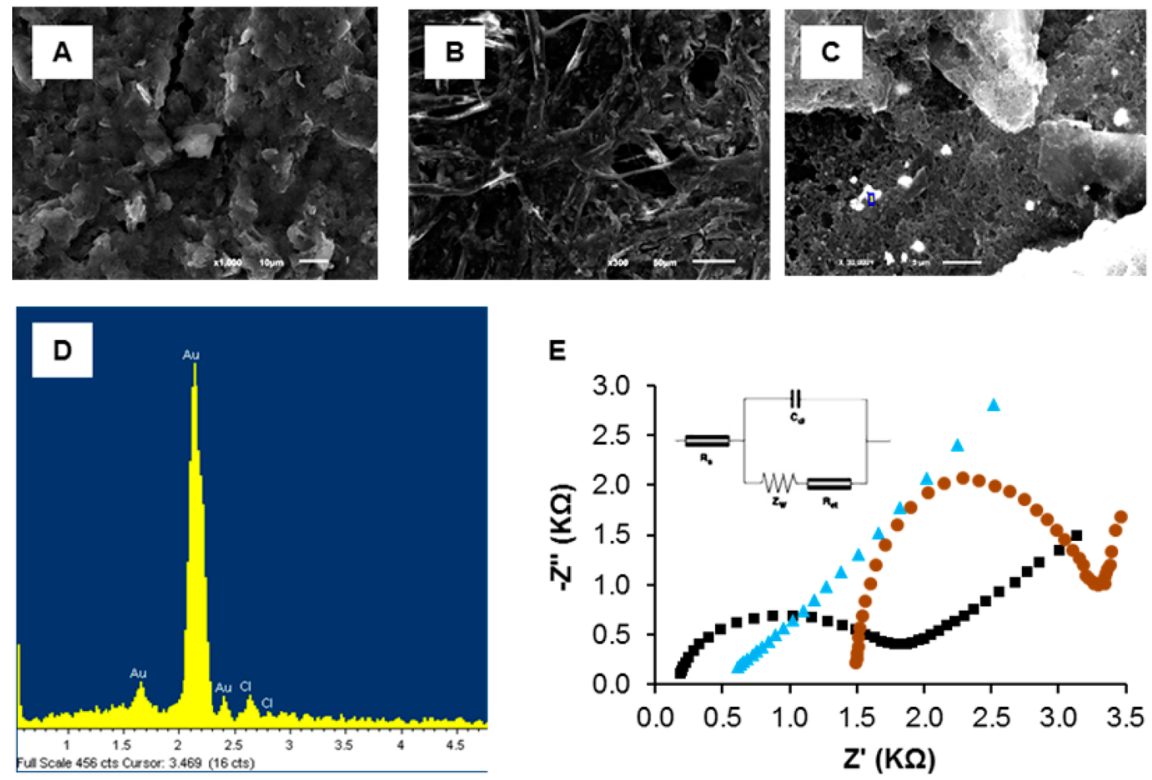

Figure 3. Scanning electron microscopy images of a PCWE X1000 (A) and a AuNPs-PCWE, X300 (B) and X30000 (C); EDX spectrum obtained from AuNPs-PCWEs (D); Nyquist plots from EIS measurements in a $5 \mathrm{mM} \mathrm{K}_{4}\left[\mathrm{Fe}(\mathrm{CN})_{6}\right]$ solution in $0.1 \mathrm{M} \mathrm{PB}(\mathrm{pH} 7.0)$ at a SPCE (black $\left.\mathbf{\square}\right)$ and at a PCWE (brown -) and AuNPs-PCWE (blue $\mathbf{\Delta}$ ), coupled to SPCEs (E); the equivalent circuit used for data fitting is shown in the left upper inset (the applied potential was $+0.2 \mathrm{~V}$ ).
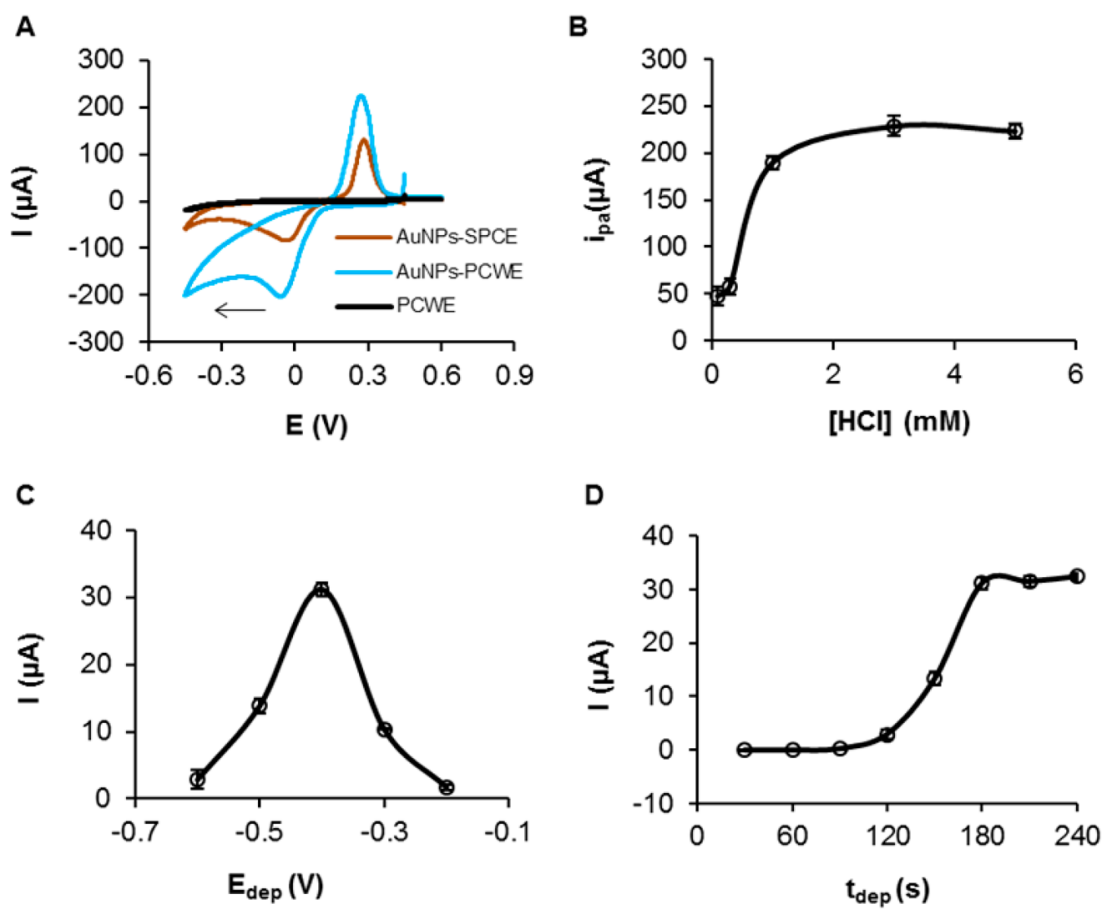

Figure 4. (A) Cyclic voltammograms recorded in $200 \mathrm{mg} \mathrm{L}^{-1} \mathrm{As}(\mathrm{III})$ solutions in $3 \mathrm{M} \mathrm{HCl}$ using an SPCE, a PCWE coupled to a SPCE, and a AuNPs-PCWE also coupled to a SPCE. Scan rate, $100 \mathrm{mV} \mathrm{s}^{-1}$. (B) Effect of increasing $\mathrm{HCl}$ concentration on the stripping anodic current obtained in $200 \mathrm{mg} \mathrm{L}^{-1} \mathrm{As}(\mathrm{III})$ solutions measured by cyclic voltammetry. Scan rate: $100 \mathrm{mV} \mathrm{s}^{-1}$. Influence of $(\mathrm{C})$ the deposition potential $\left(t_{\mathrm{dep}}=180 \mathrm{~s}\right)$ and (D) the deposition time $\left(E_{\text {dep }}=-0.3 \mathrm{~V}\right)$ on the chronoamperometric signal $\left(E=+0.4 \mathrm{~V}\right.$, $\left.t_{\text {meas }}=30 \mathrm{~s}\right)$ recorded in a $200 \mu \mathrm{g} \mathrm{L}^{-1} \mathrm{As}(\mathrm{III})$ solution in 3 $\mathrm{M} \mathrm{HCl}$. Error bars correspond to the standard deviation $(n=3)$.

ensured the whole oxidation of $\mathrm{As}(0)$ to $\mathrm{As}(\mathrm{III})$ without compromising the stability of AuNPs (see Figure S4).

The plot of the analytical signal (current measured at a fixed time in the anodic stripping chronoamperogram) versus the deposition potential (Figure 4C) shows that the highest stripping response in a $20 \mu \mathrm{g} \mathrm{L} \mathrm{L}^{-1} \mathrm{As}$ (III) solution (in $3 \mathrm{M}$ $\mathrm{HCl}$ ) was observed at a deposition potential of $-0.3 \mathrm{~V}$. This value was chosen for further experiments. Potentials below this value could be responsible for an inefficient reduction of As(III). For more negative values, the decrease on the analytical response could be due to the hydrogen generation. Figure 4D shows the influence of the deposition time upon the chronoamperometric stripping response. The current measured at $30 \mathrm{~s}$ increased within deposition times comprised between 
A

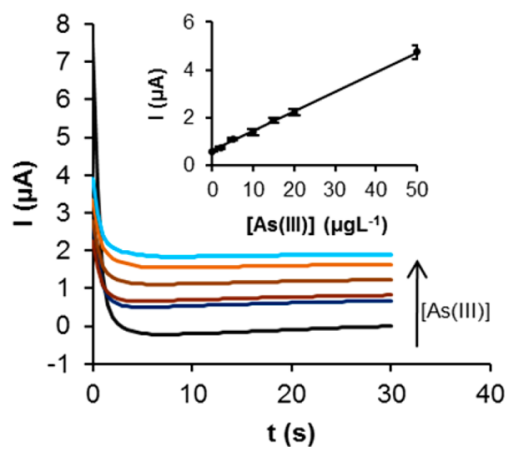

B

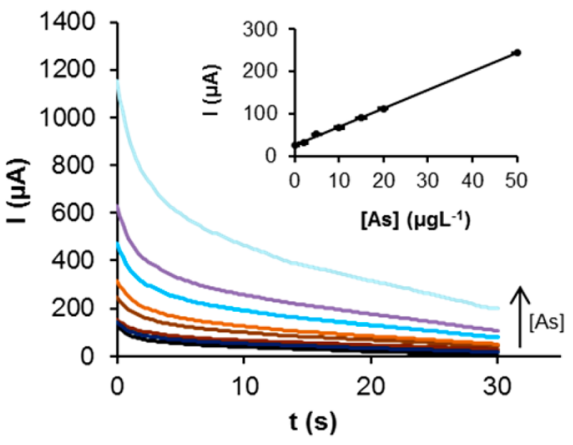

Figure 5. Stripping chronoamperograms obtained by using AuNPs-PCWEs for (A) As(III) and (B) total As (including iodide in the medium) solutions with different concentrations. Insets show the corresponding calibration plots. $E_{\text {dep }}=-0.3 \mathrm{~V}, t_{\text {dep }}=180 \mathrm{~s}, E_{\text {strip }}=+0.4 \mathrm{~V} ; t_{\text {strip }}=30 \mathrm{~s}$.

120 and 180 s. At higher deposition times, the signal became almost independent of the deposition time, suggesting a saturation of the electrode surface. ${ }^{58}$ As a compromise between reasonable analysis time and signal, $180 \mathrm{~s}$ was selected as the most appropriate deposition time for further applications. A stripping potential of $+0.4 \mathrm{~V}$ was chosen to ensure that all the deposited $\mathrm{As}(0)$ is oxidized to As(III).

Calibration Curve and Determination of As(III), Total As, and $A s(V)$ in Real Samples. The feasibility of using AuNPs-PCWEs to determine inorganic arsenic in real samples was evaluated. A calibration (Figure 5A) was carried out by anodic stripping chronoamperometry of the deposited As $(0)$. Initial As(III) solutions were prepared between 2 and $50 \mu \mathrm{g} \mathrm{L}^{-1}$ in $3 \mathrm{M} \mathrm{HCl}$ and $\mathrm{As}(0)$ was deposited at $-0.3 \mathrm{~V}$ during $180 \mathrm{~s}$. Then, a potential of $+0.4 \mathrm{~V}$ was applied and chronoamperograms ( $I$ vs $t$ curves) were recorded, measuring the current obtained at $30 \mathrm{~s}$. A linear relationship between the current and the concentration of As(III) was obtained in this range with $R^{2}$ $=0.9992$. The sensitivity was $0.083 \mu \mathrm{A} \mathrm{L} \mu \mathrm{g}^{-1}$ and the limit of detection (LOD) was $2.2 \mu \mathrm{g} \mathrm{L}^{-1}$. This value was calculated according to the $3 S_{\mathrm{b}} / m$ criterium, where $m$ is the slope of the linear range and $S_{\mathrm{b}}$ the standard deviation of the intercept. As(III) can be selectively determined in the presence of As(V) by choosing a background electrolyte or potential at which As $(V)$ is not reduced. However, under the conditions at which As(V) can be electrochemically reduced, As(III) will also accumulate on the electrode, with different kinetics. ${ }^{37}$ In addition, such negative overpotential causes interferences because of the hydrogen generation which could affect the precision. $^{34}$ On the other hand, As $(\mathrm{V})$ can be determined indirectly as the difference between the total arsenic and different As(III) concentrations. ${ }^{59,60}$ To get the total concentration, the chemical reduction of As species to As(III) was carried out in presence of reducing agents before recording the electrochemical measurement. In this case, total As concentration has been obtained by chronoamperometric stripping of $\mathrm{As}(0)$ from $\mathrm{As}(\mathrm{III})$ generated after the reduction of As(V) to As(III) with $\mathrm{KI}$ in $3 \mathrm{M} \mathrm{HCl}$. Since the chronoamperometric signal could be affected by the presence of iodide ions, the calibration curve was repeated including $\mathrm{KI}$ in calibration solutions. Then, samples and calibration solutions were treated in the same way. The stock solution consisted of a 1:1 mixture of $1 \mathrm{mg} \mathrm{L}^{-1} \mathrm{As}(\mathrm{III})$ and $1 \mathrm{mg} \mathrm{L}^{-1} \mathrm{As}(\mathrm{V})$ standard solutions in $3 \mathrm{M} \mathrm{HCl}$. Both, sample and stock solutions were diluted 2:3 with $\mathrm{KI}$ and $\mathrm{HCl}$ (final concentrations of 0.2 and 3 $\mathrm{M}$ for $\mathrm{KI}$ and $\mathrm{HCl}$, respectively). Finally, they were heated at 80
${ }^{\circ} \mathrm{C}$ for 5 min to reduce chemically $\mathrm{As}(\mathrm{V})$ to As(III). Once all the As was in the form of As(III), chronoamperometric stripping was performed using the same conditions as those used when As(III) was determined in absence of As(V). Figure $5 \mathrm{~B}$ shows the calibration curve obtained by representing the current measured at $30 \mathrm{~s}$ from chronoamperograms recorded at $+0.4 \mathrm{~V}$ after As(V) chemical reduction followed by $\mathrm{As}(0)$ electrodeposition at $-0.3 \mathrm{~V}$ during $180 \mathrm{~s}$.

Concentrations of total As were comprised between 2 and 50 $\mu \mathrm{g} \mathrm{L}^{-1}$ (i.e., $1 \mu \mathrm{g} \mathrm{L}^{-1}$ of $\mathrm{As}(\mathrm{III})$ and $1 \mu \mathrm{g} \mathrm{L}^{-1}$ of $\mathrm{As}(\mathrm{V})$ and 25 $\mu \mathrm{g} \mathrm{L}^{-1}$ of As(III) and $25 \mu \mathrm{g} \mathrm{L}^{-1}$ of As(V)) in $3 \mathrm{M} \mathrm{HCl}$. A linear relationship was obtained in the range assayed with an $R^{2}=$ 0.9990 . The average slope (sensitivity) was $4.4 \mu \mathrm{A} \mathrm{L} \mu \mathrm{g}^{-1}$. The limit of detection (LOD) found was $2.4 \mu \mathrm{g} \mathrm{L} \mathrm{L}^{-1}$. This was calculated according to the $3 S_{\mathrm{b}} / \mathrm{m}$ criterium, and it agrees with the value obtained before for As(III) in a medium without KI.

Three real white wine samples obtained from a local market were analyzed using AuNPs-PCWEs coupled to SPCEs. Results obtained with the developed methodology were compared with those obtained by ICP-MS. Table 2 shows the results obtained in both methods.

Table 2. Results for As(III) and Total As Determination at White Wines with Both the Electrochemical Method Developed in This Work and an Established ICP-MS Method, Used As the Reference for Validation

\begin{tabular}{cccccc} 
& \multicolumn{3}{c}{ stripping chronoamperometry } & & ICP-MS \\
\cline { 2 - 4 }$(\mathrm{III})$ & As(III) $\left(\mu \mathrm{g} \mathrm{L}^{-1}\right)$ total & $\begin{array}{c}\text { As }(\mathrm{V})^{a} \\
\left(\mu \mathrm{g} \mathrm{L}^{-1}\right)\end{array}$ & $\begin{array}{c}\text { As }\left(\mu \mathrm{g} \mathrm{L}^{-1}\right) \\
1\end{array}$ & $\begin{array}{c}\text { total As } \\
\left(\mu \mathrm{g} \mathrm{L}^{-1}\right)\end{array}$ & \\
1 & $1.7 \pm 0.2$ & $1.7 \pm 0.2$ & $2.7 \pm 0.7$ & & $5.0 \pm 0.5$ \\
& & $4.4 \pm 0.5$ & & \\
2 & $1.2 \pm 0.33 .6 \pm 0.4$ & $3.6 \pm 0.4$ & $2.4 \pm 0.7$ & $3.8 \pm 0.3$ \\
3 & $1.5 \pm 0.1$ & $1.5 \pm 0.1$ & $2.5 \pm 0.6$ & $4.2 \pm 0.2$ \\
& & $4.0 \pm 0.5$ & &
\end{tabular}

${ }^{a}$ Calculated as the difference between total As and As(III) concentrations. The error was calculated by propagation of As(III) and total As errors.

The $t$-Student's test demonstrated that there were no significant differences between the values given by ICP-MS and those obtained with our paper-based nanostructured electrochemical platform at a 0.05 significance level. This indicates the good accuracy and precision achieved.

Finally, economic aspects of drop-casted PCWEs fabrication have been compared with those involved in the production of stencil-printed PCWEs.Table S1 shows the cost is more 
favorable to drop-casted PCWEs. Moreover, as can be seen in the pictures of the discs (front and back sides) obtained by both methodologies, shown in Figure S6, the paper becomes more impregnated with the ink suspension.

\section{CONCLUSIONS}

We have developed an alternative, reproducible, and sustainable method for the nanostructuration of paper working electrodes based on carbon ink with AuNPs generated by CV. The combination of carbon ink PWEs with robust well-known platforms such as SPCEs, with their own external reference and counter electrodes, provides a reproducible electrochemical growth of AuNPs. Portability, low cost, and disposability are properties shared by both, paper WEs and ceramic SPEs, very useful platforms for obtaining a great amount of data. On the other hand, the fabrication of carbon electrodes on paper substrates by drop casting has a lower cost than paper stencilprinted substrates. The method developed here is a clean procedure which does not require the use of masks, simplifying the fabrication process (then decreasing the time and costs) and making it suitable for decentralized analysis or determinations in low-resource areas. Data could be obtained in a fast manner if assays are performed in parallel (with multipotentiostatic facilities). To demonstrate its potential, inorganic arsenic (As(III) and As(V)) have been accurately and precisely determined in white wines, with results that are in agreement with those obtained by ICP-MS (only total As could be determined). As(III) redox processes were notoriously improved with the use of gold nanostructures. We have shown that the platform AuNPs-PCWEs is useful for simple and low-cost determination of As in food analysis.

\section{ASSOCIATED CONTENT}

\section{S Supporting Information}

The Supporting Information is available free of charge on the ACS Publications website at DOI: 10.1021/acs.analchem.7b00144.

Cyclic voltammogram recorded between +1.0 and -0.4 $\mathrm{V}$ in $10.15 \mathrm{mM} \mathrm{AuCl}_{4}^{-}$(in $2 \mathrm{M} \mathrm{HCl}$ ) on a PCWE coupled to a SPCE; cyclic voltammograms recorded for gold electrogeneration (in $10.15 \mathrm{mM} \mathrm{AuCl}_{4}^{-}$, in $2 \mathrm{M}$ $\mathrm{HCl}$ ) scanning the potential in different windows to show the $\mathrm{H}_{2}$ desorption process; multicyclic voltammograms (45 cycles) performed for nanostructuration of a PCWE with gold; cyclic voltammogram recorded between +1.5 and $-0.6 \mathrm{~V}$ in a solution of As(III) (in 3 $\mathrm{M} \mathrm{HCl}$ ) on a AuNPs-PCWE coupled to a SPCE; anodic stripping voltammograms recorded on a AuNPs-PCWE in a solution of $\mathrm{As}$ (III) in different $\mathrm{HCl}$ concentrations; estimation of the cost of PCWEs depending on the methodology employed for paper-based electrode fabrication (PDF)

\section{AUTHOR INFORMATION}

\section{Corresponding Author}

*Phone: +34 (9)85102968. Fax: + 34 (9)85103125. E-mail: mtfernandeza@uniovi.es.

\section{ORCID ${ }^{\circ}$}

Agustín Costa-García: 0000-0002-7630-1497

M. Teresa Fernández-Abedul: 0000-0003-3782-5025

\section{Notes}

The authors declare no competing financial interest.

\section{ACKNOWLEDGMENTS}

This work has been supported by the Spanish Ministry of Economy and Competitiveness (MINECO) under Projects CTQ2011-25814 and CTQ2014-58826-R. E. Nunez-Bajo thanks MINECO for the award of a Ph.D. Grant BES-2012056713. Authors thank Prof. E. Blanco-González, Prof. M. Montes-Bayón, and J. Garcia-Fernández from the Departamento de Química Física y Analítica, Universidad de Oviedo, for kindly determining the total arsenic concentration in white wines by ICP-MS.

\section{REFERENCES}

(1) Botasini, G. H.; Méndez, E. Anal. Chim. Acta 2013, 800, 1-11.

(2) Top Ten Trends Driving Science. http://axial.acs.org/2016/12/12/ 10-big-ideas/ (accessed January 10, 2017).

(3) Nemiroski, A.; Christodouleas, D. C.; Hennek, J. W.; Kumar, A. A.; Maxwell, E. J.; Fernández-Abedul, M. T.; Whitesides, G. M. Proc. Natl. Acad. Sci. U. S. A. 2014, 111, 11984-11989.

(4) García-González, R; Costa-García, A.; Fernández-Abedul, M. T. Sens. Actuators, B 2014, 198, 302-308.

(5) Glavan, A. C.; Ainla, A.; Hamedi, M. M.; Fernández-Abedul, M. T.; Whitesides, G. M. Lab Chip 2016, 16, 112-119.

(6) Rama, E. C.; Costa-García, A.; Fernández-Abedul, M. T. Biosens. Bioelectron. 2017, 88, 34-40.

(7) Fernández-la-Villa, A.; Sánchez-Barragán, D.; Pozo-Ayuso, D. F.; Castaño-Álvarez, M. Electrophoresis 2012, 33, 2733-2742.

(8) Richter, E. M.; Tormin, T. F.; Cunha, R. R.; Silva, W. P.; PérezJunquera, A.; Fanjul-Bolado, P.; Hernández-Santos, D.; Muñoz, R. A. A. Electroanalysis 2016, 28, 1856-1859.

(9) Bakker, E. ACS Sensors 2016, 1, 838-841.

(10) García-González, R.; Costa-García, A.; Fernández-Abedul, M. T. Sens. Actuators, B 2014, 202, 129-136.

(11) Fernández-Abedul, M. T.; Costa-García, A. Anal. Bioanal. Chem. 2008, 390, 293-298.

(12) Martínez-Paredes, G.; González-García, M. B.; Costa-García, A. Electroanalysis 2009, 21, 925-930.

(13) Castañeda, M. T.; Merkoci, A.; Pumera, M.; Alegret, S. Biosens. Bioelectron. 2007, 22, 1961-1967.

(14) Yañez-Sedeno, P.; Pingarron, J. M. Anal. Bioanal. Chem. 2005, 382, 884-886.

(15) Luo, X.; Morrin, A.; Killard, A. J.; Smyth, M. R. Electroanalysis 2006, 18, 319-326.

(16) Martínez-Paredes, G.; González-García, M. B.; Costa-García, A. Electrochim. Acta 2009, 54, 4801-4808.

(17) Dungchai, W.; Chailapakul, O.; Henry, C. S. Anal. Chem. 2009, $81,5821-5826$.

(18) Nie, Z.; Nijhuis, C. A.; Gong, J.; Chen, X.; Kumachev, A.; Martinez, A. W.; Narovlyansky, M.; Whitesides, G. M. Lab Chip 2010, 10, 477-483.

(19) Mettakoonpitak, J.; Boehle, K.; Nantaphol, S.; Teengam, P.; Adkins, J. A.; Srisa-Art, M.; Henry, C. S. Electroanalysis 2016, 28, $1420-1436$.

(20) Scida, K.; Cunningham, J. C.; Renault, C.; Richards, I.; Crooks, R. M. Anal. Chem. 2014, 86, 6501-6507.

(21) Fosdick, S. E.; Anderson, M. J.; Renault, C.; DeGregory, P. R.; Loussaert, J. A.; Crooks, R. M. Anal. Chem. 2014, 86, 3659-3666.

(22) Adkins, J. A.; Henry, C. S. Anal. Chim. Acta 2015, 891, 247254.

(23) Núnnez-Bajo, E.; Blanco-López, M. C.; Costa-García, A.; Fernández-Abedul, M. T. Biosens. Bioelectron. 2017, 91, 824-832.

(24) Hamedi, M. M.; Ainla, A. A.; Guder, F.; Christodouleas, D. C.; Fernández-Abedul, M. T.; Whitesides, G. M. Adv. Mater. 2016, 28, 5054-5063. 
(25) Glavan, A. C.; Christodouleas, D.; Mosadegh, B.; Yu, H. D.; Smith, B.; Lessing, J.; Fernández-Abedul, M. T.; Whitesides, G. M. Anal. Chem. 2014, 86, 11999-12007.

(26) Lessing, J.; Glavan, A. C.; Walker, S. B.; Keplinger, C.; Lewis, J. A.; Whitesides, G. M. Adv. Mater. 2014, 26, 4677-4682.

(27) Amor-Gutierrez, O.; Rama, E. C.; Costa-Garcia, A.; FernandezAbedul, M. T. Biosens. Bioelectron. 2017, 93, 40-45.

(28) Liu, W.; Ge, L.; Yan, M.; Yan, J.; Huang, J.; Yu, J. Biosens. Bioelectron. 2013, 49, 111-117.

(29) Guntupalli, B.; Liang, P.; Lee, J.; Yan, Y.; Yu, H.; Canoura, J.; He, J.; Li, W.; Wenzhi, L.; Weizmann, Y.; Xiao, Y. ACS Appl. Mater. Interfaces 2015, 7, 27049-27058.

(30) Sultana, I.; Razaq, A.; Idrees, M.; ASif, M. H.; Ali, H.; Arshad, A.; Iqbal, S.; Ramay, S. M.; Hussain, S. Q. J. Electron. Mater. 2016, 45, $5140-5145$

(31) Domínguez-Renedo, O.; Ruiz-Espelt, L.; García-Astorgano, N.; Arcos-Martínez, M. J. Talanta 2008, 76, 854-858.

(32) Crane, M.; Kwok, K. W. H.; Wells, C.; Whitehouse, P.; Lui, G.

C. S. Environ. Sci. Technol. 2007, 41, 5014-5021.

(33) Martín Yerga, D.; Álvarez-Martos, I.; Blanco-López, M. C.; Henry, C. S.; Fernández-Abedul, M. T. Anal. Chim. Acta 2017, (under revision).

(34) Ibanez, J. G.; Carreon-Alvarez, A.; Barcena-Soto, M.; Casillas, N. J. Food Compos. Anal. 2008, 21, 672-683.

(35) Compendium of international methods of analysis OIV. Maximum acceptable limits of various substances contained in wine. http://www.oiv. int/js/lib/pdfjs/web/viewer.html?file=/public/medias/2601/oiv-mac1-01.pdf (accessed March 15, 2016).

(36) Dopp, E.; Hartmann, L. M.; Florea, A. M.; Von Recklinghausen, U.; Pieper, R.; Shokouhi, B.; Rettenmeier, A. W.; Hirner, A. V.; Obe, G. Toxicol. Appl. Pharmacol. 2004, 201, 156-165.

(37) Antonova, S.; Zakharova, E. Electrochem. Commun. 2016, 70, $33-38$.

(38) Dai, X.; Nekrassova, O.; Hyde, M. E.; Compton, R. G. Anal. Chem. 2004, 76, 5924-5929.

(39) Xiao, L.; Wildgoose, G. G.; Compton, R. G. Anal. Chim. Acta

2008, 620, 44-49.

(40) Liu, Z.-G.; Huang, X.-J. TrAC, Trends Anal. Chem. 2014, 60, $25-35$.

(41) Chen, H.-H.; Huang, J.-F. Anal. Chem. 2014, 86, 12406-12413. (42) Lan, Y.; Luo, H.; Ren, X.; Wang, Y.; Wang, L. Anal. Lett. 2012, $45,1184-1196$

(43) Majid, E.; Hrapovic, S.; Liu, Y.; Male, K. B.; Luong; J, H. T. Anal. Chem. 2006, 78, 762-769.

(44) Sakira, A. K.; Somé, I. T.; Ziemons, E.; Dejaegher, B.; Mertens, D.; Hubert, P.; Kauffmann, J. M. Electroanalysis 2015, 27, 309-316.

(45) Song, Y.-S.; Muthuraman, G.; Chen, Y.-Z.; Lin, C.-C.; Zen, J.-M. Electroanalysis 2006, 18, 1763-1770.

(46) Cinti, S.; Politi, S.; Moscone, D.; Palleschi, G.; Arduini, F. Electroanalysis 2014, 26, 931-939.

(47) Yang, M.; Chen, X.; Jiang, T.; Guo, Z.; Liu, J.; Huang, X. Anal. Chem. 2016, 88, 9720-9728.

(48) Kalvoda, R. Electroanalysis 2002, 14, 469-472.

(49) Segura, M.; Madrid, Y.; Camara, C. J. Anal. At. Spectrom. 1999, 14, 131-135.

(50) Wangkarn, S.; Pergantis, S. A. J. Anal. At. Spectrom. 1999, 14, 657-662.

(51) Sanllorente-Méndez, S.; Domínguez-Renedo, O.; ArcosMartinez, J. Electroanalysis 2009, 21, 635-639.

(52) Galuszka, A.; Migaszewski, Z.; Namiesnik, J. TrAC, Trends Anal. Chem. 2013, 50, 78-84.

(53) Dugo, G.; La Pera, L.; Lo Turco, V.; Di Bella, G. Chemosphere 2005, 61, 1093-1101.

(54) Bu, L.; Gu, T.; Ma, Y.; Chen, C.; Tan, Y.; Xie, Q.; Yao, S. J. Phys. Chem. C 2015, 119, 11400-11409.

(55) Bu, L.; Liu, J.; Xie, Q.; Yao, S. Electrochem. Commun. 2015, 59, $28-31$.

(56) Cavicchioli, A.; La-Scalea, M. A.; Gutz, G. R. Electroanalysis 2004, 16, 697-711.
(57) La Pera, L.; Saitta, M.; Di Bella, G.; Dugo, G. J. Agric. Food Chem. 2003, 51, 1125-1129.

(58) Kopanica, M.; Novotný, L. Anal. Chim. Acta 1998, 368, 211218.

(59) Cavicchioli, A.; La-Scalea, M. A.; Gutz, I. G. R. Electroanalysis 2004, 16, 697-711.

(60) Muñoz, E.; Palmero, S. Talanta 2005, 65, 613-620. 